Revista Estudios, (38), 2019.

Junio 2019-Noviembre 2019

ISSN 1659-3316

Lozano Trejo Joaquín

\title{
Dossier
}

México y Centroamérica

\section{Gonzalo Robles y la Oficina de Investigaciones Industriales del Banco de México. Un costarricense en el impulso a la industrialización mexicana, 1942-1952.}

\author{
Joaquín Lozano Trejo \\ Acervo Histórico Diplomático \\ Secretaría de Relaciones Exteriores, México \\ quino1274@yahoo.com.mx \\ http://orcid.org/0000-0002-7782-2980
}

Recibido: 30 de abril de 2019

Aceptado: 20 de mayo de 2019

Resumen: De origen costarricense, Gonzalo Robles llegó a nuestro país a principios del siglo XX en donde realizó sus estudios superiores en la Escuela Nacional de Agricultura, precisamente durante el estallido de la Revolución Mexicana. Robles tuvo un papel destacado en las instituciones mexicanas de la posrevolución, para efectos de este trabajo, se analizará la labor del personaje en el establecimiento de la Oficina de Investigaciones Industriales, cuyo objetivo fue contribuir al proyecto de industrialización que se impulsó en el país. Su pensamiento y esfuerzos realizados en esta materia constituyen el objetivo central del mismo.

Palabras claves: Costa Rica; instituciones; industrialización; investigación; desarrollo

Gonzalo Robles and the Office of Industrial Investigations of the Bank of Mexico. A Costa Rican in the drive to Mexican industrialization, 1942-1952.

Abstract: Origin of Costa Rica, Gonzalo Robles arrived in our country at the beginning of the 20th century where he completed his studies at the National School of Agriculture, precisely during the outbreak of the Mexican Revolution. Robles played a leading role in the Mexican institutions of the post-revolution, for the purposes of this work, the character's work will be analyzed in the

\section{(c) (i) (2) (2)}

La Revista Estudios es editada por la Universidad de Costa Rica y se distribuye bajo una Licencia Creative Commons Atribución-NoComercial-CompartirIgual 3.0 Costa Rica. Para más información envíe un mensaje a revistaestudios.eeg@ucr.ac.cr. 
Revista Estudios, (38), 2019.

Junio 2019-Noviembre 2019

ISSN 1659-3316

Lozano Trejo Joaquín

establishment of the Office of Industrial Research, whose objective was to contribute to the industrialization project that was promoted in the country. His thought and efforts made in this matter are the central objective of it.

Keyword: Costa Rica; institutions; industrialization; research; development

\section{Un costarricense en las instituciones mexicanas}

En ocasiones, las vocaciones profesionales se despliegan de manera independiente del lugar al que la vida lleve circunstancialmente a un individuo. No pudiéndolo hacer en la patria de origen, otros escenarios nacionales pueden presentar condiciones más propicias para que el talento encuentre espacio y sentido. Tal fue el caso del costarricense Gonzalo Robles Fernández quien tuvo en México, no sólo una segunda patria, sino también, la oportunidad de colaborar desde sus posibilidades, en la construcción institucional del Estado emanado de la Revolución.

En este sentido, la participación en la creación y consolidación de las instituciones gubernamentales del México contemporáneo por parte de Robles Fernández fue diversa e intensa, atravesando diversos ámbitos, principalmente: el agrícola, el financiero y el industrial. En todos ellos, dejó constancia del talento de su acción y pensamiento, así como de los afectos y reconocimientos obtenidos. La importancia de lo anterior evitó que escasamente, se acudiera a su condición de extranjero para descalificarlo o marginarlo.

Su gran capacidad de estudio y análisis de las realidades políticas, económicas y sociales del momento, le redituaron en su inclusión en los grupos técnicos e intelectuales que participaron del diseño y operación de las políticas institucionales de los gobiernos posrevolucionarios, atendiendo la vertiente nacionalista de desarrollo económico. En este punto es necesario señalar, que está afirmación, lejos de implicar una visión en extremo localista, manifestaba una posición con alcances regionales, es decir, latinoamericanos; con lo que,

\section{(c) (1)(2)}

La Revista Estudios es editada por la Universidad de Costa Rica y se distribuye bajo una Licencia Creative Commons Atribución-NoComercial-CompartirIgual 3.0 Costa Rica. Para más información envíe un mensaje a revistaestudios.eeg@ucr.ac.cr. 
ISSN 1659-3316

Junio 2019-Noviembre 2019

Lozano Trejo Joaquín

guardando las diferencias particulares de contexto, conectaba las realidades de sus dos patrias y universalizaba su pensamiento.

La inserción de Gonzalo Robles en el medio político mexicano es considerada como parte de la generación que, siendo estudiantes en 1915, se involucraron en la dinámica revolucionaria en alguna de las facciones que contendieron y definieron el rumbo del Estado que surgió de esa conflagración. De tal forma que su formación profesional fue complementada con su experiencia en los campos de batalla, pero principalmente, en los proyectos que, desde esos escenarios, ya trazaban los caudillos y que más tarde tomarían forma en políticas o programas de gobierno.

Así, al seguir la vida profesional de nuestro personaje, en realidad damos seguimiento a la trama de los lineamientos fundamentales que los gobiernos posrevolucionarios vislumbraron como necesarios atender, ante la insuficiencia que en ese ámbito había mostrado el régimen porfirista y que de alguna manera lo había llevado al estallamiento armado. Ingenieros civiles, agrónomos, abogados, economistas, artistas, entre otros, se fueron formando al calor de las problemáticas económico-sociales, desplegando su creatividad en cuanto a los proyectos e instituciones necesarias para darle solución.

Este texto se desprende de una investigación más amplia sobre el papel el proceso de industrialización mexicano de mediados del siglo $X X$ y en el que Robles Fernández tuvo una notable participación a través de la dirección de la Oficina de Investigaciones Industriales del Banco de México. Es precisamente su pensamiento respecto a este proceso y su concreción en dicho organismo, del que damos cuenta aquí, antecediéndolo de algunos datos biográficos que revelan la importancia del personaje como partícipe de las instituciones que dieron forma al México contemporáneo, atendiendo los problemas esenciales a los que se enfrentó.

\section{(C) $(\Theta \odot$}

La Revista Estudios es editada por la Universidad de Costa Rica y se distribuye bajo una Licencia Creative Commons Atribución-NoComercial-CompartirIgual 3.0 Costa Rica. Para más información envíe un mensaje a 
Revista Estudios, (38), 2019.

Junio 2019-Noviembre 2019

ISSN 1659-3316

Lozano Trejo Joaquín

\section{Biografía de un funcionario}

Las aspiraciones profesionales de este personaje nacido en la provincia de Cartago, Costa Rica - a escasa distancia de la capital, San José-, el 27 de marzo de 1892, se empezaron a conformar quizá, en el propio seno familiar. Su padre, J. Marcelino Robles Arias se distinguió por su participación pública:

Fue Gobernador de la Provincia, miembro del Congreso Constitucional y ocupó cargos en varias Juntas Electorales; Presidente de Educación del Cantón Central de Cartago; Agente activo del Banco de Costa Rica y en sus últimos años había sido tesorero de la Junta de Caridad, de la Junta Edificadora de los Ángeles, del Asilo de los Ancianos y del Patrimonio de los Pobres. (Dávalos, 2014, p. 46)

Por su parte, su madre, Elisa Fernández Jiménez, fue inspectora escolar y uno de sus hermanos, del que se tiene noticia, Enrique, migró a Estados Unidos para estudiar ingeniería. La aspiración a una formación profesional y su consecuente desarrollo, encontraban razón de ser en el contexto familiar, pero también, en el social. En efecto, independientemente de las vicisitudes y particularidades de la política costarricense de la época, en las postrimerías del siglo XIX y los inicios del XX predominaron los de gobiernos de corte liberal quienes, dentro de los márgenes de las posibilidades efectivas del país, consolidaron el Estado costarricense y lograron cierta estabilidad financiera, lo que permitió a determinados grupos sociales el acceso a la educación y otros bienes culturales.

En este marco de posibilidades, Gonzalo realizó sus estudios de bachillerato en Ciencias Sociales y Humanidades en su país natal. Los problemas financieros que sufrió la familia dificultaron el seguimiento de sus estudios superiores. Sin embargo, aprovechando las redes familiares, particularmente de aquellos costarricenses que se encontraban en el extranjero, aceptó la invitación de un tío, primo segundo de su madre, para emigrar en 1907 a la ciudad de Chicago, Illinois, en los Estados Unidos. Con su nueva familia no logró sentirse a gusto, por lo que decidió marchar a México, a la ciudad de Guadalajara, Jalisco,

La Revista Estudios es editada por la Universidad de Costa Rica y se distribuye bajo una Licencia Creative Commons Atribución-NoComercial-CompartirIgual 3.0 Costa Rica. Para más información envíe un mensaje a 
ISSN 1659-3316

Junio 2019-Noviembre 2019

ahora buscando el cobijo de otro tío, hermano de su padre, Juan Agustín Robles Arias. En esa ciudad permaneció, hasta que:

Por fin, en 1909, Juan Agustín, su anfitrión en Guadalajara, le consiguió una beca en la Escuela Nacional de Agricultura, ubicada en San Jacinto, D.F. e ingresó de inmediato a realizar los estudios que anhelaba. (...) Su estancia de cuatro años en la escuela de agricultura, le redituó grandes amigos como Marte R. Gómez, Waldo Soberón y otros más, todos ellos destacarían posteriormente desempeñando cargos importantes en el desenvolvimiento del área agrícola. (Giles, 1988, p. 6)

Así, su llegada al país y, por tanto, su incorporación a la vida académica se da en el último minuto del régimen porfirista, precisamente en una de sus instituciones emblemáticas por lo que refiere a la formación de profesionistas en uno de los campos productivos dominantes en ese momento: la agricultura. México, como la mayoría de los países latinoamericanos, mantenían desde los tiempos de la conquista y la colonización europea, una larga tradición como productores y exportadores de materias primas y bienes alimenticios por medio de unidades productivas de gran extensión, las haciendas. Por lo que el campo de desarrollo profesional de los egresados de la Escuela Nacional de Agricultura (ENA) encontraba cauce en esa estructura.

Pero prácticamente al momento de su incorporación, el país inició una serie de transformaciones que afectarían el devenir de los estudiantes de esa escuela. La sucesión de acontecimientos que en primera instancia desencadenarían la Revolución Mexicana y que posteriormente le dieron curso, abrieron posibilidades políticas, ideológicas e institucionales, a las que gradualmente se fueron adscribiendo.

En ese marco, Gonzalo Robles no sólo tuvo la oportunidad de establecer relaciones de amistad con personajes que luego sería nodales en la construcción del Estado posrevolucionario si no que él mismo participó de las simpatías al maderismo primero, y posteriormente sumándose al ejército constitucionalista al asesinato de Francisco I. Madero y José María Pino Suárez, tras el cual, el

La Revista Estudios es editada por la Universidad de Costa Rica y se distribuye bajo una Licencia Creative Commons Atribución-NoComercial-CompartirIgual 3.0 Costa Rica. Para más información envíe un mensaje a 
ISSN 1659-3316

Lozano Trejo Joaquín

gobierno de Victoriano Huerta cobró represalias contra la ENA: "cuando el General Bravo empezó a usar nuestro paredón de tiro para fusilar gente, la cosa se exacerbó; los muchachos empezaron a irse unos con Villa, otros con Zapata y otros nos fuimos con Carranza." (Dávalos, 2014, p. 30)

Desde su incorporación a uno de los batallones carrancistas, Robles se destacó por su capacidad intelectual, por lo que fue considerado no para las acciones militares, sino específicamente, para ir preparando los proyectos que se podrían convertir en acciones de gobierno al triunfo de la Revolución. En esos términos se expresaba el Gral. Norzagaray, al mando de la brigada carrancista acampada en el estado de Veracruz: "A este muchacho no lo llevaré a la campaña; lo dejaré en la capital, en el desempeño de otras comisiones... Aunque se ofenda lo dejaré aquí. Sería una lástima que se perdiera un hombre de esta categoría intelectual" (Dávalos, 2014, p. 37)

Evidentemente, uno de los principales problemas que las distintas facciones revolucionarias tuvieron que atender fue el agrario, tanto el asunto de la distribución de la propiedad, como el de mejoras en la técnica y en la organización productiva. $\mathrm{Y}$ fue precisamente dentro de la estructura y proyección que al respecto desarrolló el carrancismo, que Robles en consonancia con su formación como ingeniero agrícola encontró lugar como segundo Ingeniero de la Comisión Local Agraria en el estado de Veracruz. Esa responsabilidad le permitió viajar junto con un grupo de personas a Estados Unidos y Argentina, con el fin de estudiar el funcionamiento de las escuelas agrícolas en esos países. Si bien lo aprendido en dicho viaje no fue de aplicación inmediata, si le sirvió como un bagaje muy significativo para ser empleado posteriormente.

Sintiendo la necesidad de complementar sus estudios como ingeniero agrícola, ese mismo año que regresó del mencionado viaje (1916), volvió a hacer maletas, esta vez para realizar estudios de ingeniería civil en Indiana, Estados Unidos. De regreso en México hacia 1920, volvió a encontrarse con los amigos de la ENA, algunos de ellos ya formaban parte del gobierno, por lo que sus

\section{(c) (i) (2)}

La Revista Estudios es editada por la Universidad de Costa Rica y se distribuye bajo una Licencia Creative Commons Atribución-NoComercial-CompartirIgual 3.0 Costa Rica. Para más información envíe un mensaje a 
recomendaciones le sirvieron para que él mismo pudiera ingresar formando parte del proceso de reconstrucción institucional.

En ese año formó parte del Comité Reorganizador de los Ferrocarriles Nacionales de México, junto con personajes como Daniel Cosío Villegas y Jesús Silva Herzog. Al año siguiente, ya entrado en el gobierno el Gral. Álvaro Obregón, se le encargó la Dirección Nacional de Agricultura, que se ubicaba precisamente en su antigua escuela. Desde esa responsabilidad, organizó los Congresos Agronómicos, que servirían para consolidar amistades y postulados con sus antiguos compañeros en torno a sus tesis agraristas.

Pero su ejercicio en esta dirección, también le implicó viajar nuevamente para recabar información sobre la enseñanza y las técnicas agrícolas. Así, en 1923 retomó de alguna manera aquel viaje de 1916 que había iniciado por Estados Unidos y Argentina para prolongarlo ahora, a los confines del mundo y ampliando la diversidad de países a visitar. En efecto, contando con la compañía de Juan Ballesteros, iniciarían su viaje por Cuba, Estados Unidos y Canadá, para luego traspasar el Atlántico y media Europa hacia Rusia, país que estaba en ese momento a poco de convertirse en la URSS y en donde se efectuaba la Exposición Agrícola e Industrial de 1923. Después el recorrido por el resto de los países europeos: Finlandia, Suecia, Bélgica, Holanda, Alemania, Suiza, Italia, Portugal, entre otros, y a continuación regresar a América vía Brasil, Argentina, Uruguay, Chile y otros países que quedaron a su paso de regreso a México, esto último ya durante 1924 .

Amplias notas y una gran experiencia dejaron este largo viaje para Robles, mismas que tendría oportunidad de poner en marcha al inicio del gobierno del Gral. Plutarco Elías Calles. En 1925 fue llamado por el nuevo presidente para que se hiciera cargo de las Escuelas de Razas Indígenas y las Cajas Raifaisen para el crédito agrícola, según narra el propio Robles, quien pidió tiempo para analizar y más bien presentar un nuevo proyecto al respecto, ya que:

\section{(c) (i) (2)}

La Revista Estudios es editada por la Universidad de Costa Rica y se distribuye bajo una Licencia Creative Commons Atribución-NoComercial-CompartirIgual 3.0 Costa Rica. Para más información envíe un mensaje a 
(...) era inconveniente atacar el problema de la educación campesina y de la enseñanza agrícola con un criterio racial, e improcedente tratar de implantar la más evolucionada de las instituciones de crédito rural, organizada por la iniciativa de los propios interesados.

Las Escuelas Centrales Agrícolas se concibieron como parte de un sistema articulado con la educación rural, con una organización cooperativa de los ejidos y de los pequeños agricultores y con los Bancos Agrícolas Ejidales; se aspiraba a establecer en cada una de ellas... industrias de interés regional en escala importante. (Robles, 1982, p. 12)

Aceptado su proyecto fue nombrado en agosto de 1925 director de las Escuelas Centrales Agrícolas. La complejidad política del momento le dificultó su labor, sin embargo, logró impulsar las escuelas de La Huerta, Michoacán; el Mexe, Hidalgo; Santa Lucía, Durango; y San Roque, Guanajuato; las cuales evolucionarían al paso del tiempo y se convertirían en Normales Rurales. De esta forma no sólo puso en práctica lo aprendido con respecto a la enseñanza y mejoras técnicas en el campo de la agricultura, sino que inició su tránsito hacia las problemáticas financieras. Las pugnas políticas lo harían dejar la responsabilidad de las escuelas agrícolas y el gobierno callista le deparó nuevas responsabilidades al nombrarlo en 1926 gerente de la Empresa Abastecedora de Aguas de Torreón; sin embargo, su labor al respecto sería reconocida en el extranjero, tal como lo ilustra la condecoración otorgada por el gobierno de Bélgica al Mérito Agrícola de Primera Clase. ${ }^{1}$

Este sería su último empleo relacionado con el sector agrícola, ya que gradualmente y con base en su experiencia en el proyecto del Banco de Crédito Agrícola, se le asignarían responsabilidades relacionadas con la construcción de un nuevo sistema bancario que tenía como pilar el Banco de México S.A. de reciente creación. En efecto, dada la ausencia de un organismo bancario central dentro de porfiriato, los asuntos financieros estaban controlados por la banca internacional privada, así como por una diversidad de bancos locales que se

\footnotetext{
1 "Condecoración del Mérito Agrícola de Primera clase otorgada por su Majestad el Rey de los Belgas", Archivo Histórico Genaro Estrada. Secretaría de Relaciones Exteriores. Expediente III/525 (493)/2, 1926.

\section{(a) $\odot \Theta \odot$}

La Revista Estudios es editada por la Universidad de Costa Rica y se distribuye bajo una Licencia Creative Commons Atribución-NoComercial-CompartirIgual 3.0 Costa Rica. Para más información envíe un mensaje a revistaestudios.eeg@ucr.ac.cr.
} 
ISSN 1659-3316

Junio 2019-Noviembre 2019

Lozano Trejo Joaquín

dedicaban no sólo al suministro de créditos para la producción, sino que también se encargaban de la emisión de moneda; lo que dejaba en manos de particulares, funciones que se asumirían como propias del Estado.

En ese sentido, uno de los objetivos de las distintas facciones revolucionarias desde los inicios del movimiento armado, fue conseguir la creación de un organismo financiero central que controlara el manejo de la cuenta corriente del gobierno, suministrara el crédito público y llevara a cabo la emisión de moneda. $^{2}$ (Zebadúa, 1994, p. 72). Tocaría al gobierno de Calles consolidar la creación del Banco de México, así como avanzar en la conformación de un nuevo sistema bancario nacional. Para ello fue necesario desmantelar el existente y el organismo encargado de hacerlo fue el Comité liquidador de los antiguos bancos de emisión, del que formó parte junto con Narciso Bassols y Roberto Casas Alatriste durante el año de 1931.

La construcción de un nuevo sistema bancario incluía no sólo contar con un banco central, sino generar lo que se conocería como banca social o de desarrollo, la que incluía el ya mencionado Banco Central Agrícola y el Banco Nacional Hipotecario, Urbano y de Obras Públicas S.A., este último creado en 1932 y del que Robles fue su primer director, al tiempo que gestionaba su ciudadanía mexicana, la cual le fue concedida al año siguiente por el presidente Abelardo Rodríguez.

Durante su gestión en esta institución bancaria surgieron dos iniciativas trascendentales para el desarrollo económico y cultural de México. Una de ellas, la creación del fideicomiso que dio origen y rigió al Fondo de Cultura Económica a lo largo de 30 años. Junto con Eduardo Villaseñor, Emigdio Martínez Adame, Daniel Cosío Villegas, Manuel Gómez Morín y Adolfo Prieto, dieron origen a este ente en

\footnotetext{
${ }^{2}$ La necesidad de reorganizar el sistema bancario fue establecida por Venustiano Carranza en 1913, cuando manifestó la pertinencia de crear un Banco Único de Emisión y someter a la banca privada al control efectivo del Estado: "Frustrado por el apoyo que los banqueros prestaban al régimen de Huerta, Carranza amenazó que 'cambiaremos todo el actual sistema evitando el monopolio de las empresas particulares, que han absorbido por largos años la riqueza de México'. De triunfar su revolución, sentenció que 'aboliremos el derecho de emisión de billetes o papel moneda, por bancos particulares"”.
}

\section{(c) (i) (2)}

La Revista Estudios es editada por la Universidad de Costa Rica y se distribuye bajo una Licencia Creative Commons Atribución-NoComercial-Compartirlgual 3.0 Costa Rica. Para más información envíe un mensaje a revistaestudios.eeg@ucr.ac.cr. 
1934 al que posteriormente se sumarían Jesús Silva Herzog y Enrique Sarro. La otra, la Comisión de Investigaciones Industriales en la que el talento de ingenieros y economistas se conjugarían para buscar la solución a los problemas que la industrialización planteaba a nuestro país y sería la simiente del órgano que tendría un mayor desarrollo posteriormente, bajo el cobijo del Banco de México.

Con la llegada del Gral. Lázaro Cárdenas a la presidencia de la república, el ingeniero Robles fue designado director general del Banco de México, cargo que ocupó sólo nueve meses, de abril a diciembre de 1935. Hay quien explica lo efímero de su paso por esta institución a que “..., el hecho fortuito de nacer en Costa Rica y no en su querida patria adoptiva, dificultó su trabajo hasta el punto de orillarlo a renunciar." (Anaya, 2011, p. 118). Aunque más certero sería pensar que su salida formó parte de la depuración administrativa que realizó Cárdenas al expulsar del país a Plutarco Elías Calles, tal como lo parece confirmar uno de sus más cercanos colaboradores, al señalar que dentro de la turbulencia política y ante la necesidad de "neutralizar las presiones que el banco recibió para financiar el déficit presupuestal. La posición de Robles se volvió insostenible y necesariamente renunció a la dirección general..." (Robles, 1982, p. 15) (Dávalos, 2014, p. 191-92).

Su separación del ejercicio público le sirvió para ampliar las actividades relacionadas con el estudio de las problemáticas económicas nacionales e internacionales. En 1937 realizó un viaje por Estados Unidos y Europa para estudiar sus sectores industriales, y donde tuvo acceso a importantes plantas industriales de Estados Unidos. De igual forma tomó cursos en la Columbia University de Nueva York sobre "análisis económico aplicado a la industria, organización de empresas industriales, crédito, racionalización (scientific management) y desarrollo industrial." (Robles, 1982, p. 15). A su regreso al país aceptaría colaborar en la Secretaría de Relaciones Exteriores en calidad de representante de México ante el Comité de Expertos sobre el Acceso al Comercio

\section{(C) $(00$}

La Revista Estudios es editada por la Universidad de Costa Rica y se distribuye bajo una Licencia Creative Commons Atribución-NoComercial-CompartirIgual 3.0 Costa Rica. Para más información envíe un mensaje a 
ISSN 1659-3316

Junio 2019-Noviembre 2019

Lozano Trejo Joaquín

de Materia Primas, de la Sociedad de Naciones, con lo que paulatinamente se abriría su retorno a las instituciones gubernamentales.

\section{Génesis de un grupo técnico-burocrático}

Para inicios de la década de los cuarenta, ante la perspectiva de que el país pudiera iniciar un proceso de industrialización como consecuencia del incremento de la demanda externa de productos manufacturados; distintos actores sociales, llámese políticos o empresarios, vislumbraron la posibilidad de intervenir y, por lo tanto, ser partícipes de un importante crecimiento y proyección de la industria mexicana. En este marco, las instancias de tipo técnico o académico también se hicieron presentes y necesarias para acompañar de una $u$ otra forma, las acciones emprendidas por las entidades gubernamentales.

Ya desde los años veinte, la reconstrucción del país requirió de la participación de cuadros especializados en diversas materias para apoyar las medidas institucionales que se llevaron a cabo. La formación de estos se dio, en principio, en las instituciones educativas, pero de manera más pragmática, el proceso tuvo lugar en las dependencias gubernamentales como efecto de las necesidades concretas que se presentaron en el ámbito de la administración estatal, particularmente los planteados por la crisis mundial de 1929. De tal forma que:

El grupo de tecnócratas que surgieron en la década de los 1920's era muy diferente, e incluía intelectuales nacidos no del progreso porfiriano, sino de la promesa revolucionaria. Muchos de ellos, incluyendo a Daniel Cosío Villegas y Gonzalo Robles, no alcanzaron el apogeo de su influencia hasta los años 1930's y 1940's. Pero ellos comenzaron sus vidas públicas como ingenieros, investigadores y funcionarios de nivel inferior en los 1920’s. (Gauss, 2010, 30)

El papel que desempeñaron los equipos técnicos e intelectuales en esos años fue cada vez más indispensables para los gobiernos, en gran parte por la mayor complejidad que fue adquiriendo la economía y las comunicaciones entre países y 
ISSN 1659-3316

agencias internacionales. (Vernon, 1966, 154). Tradicionalmente, abogados e ingenieros principal y profesionalmente hablando, habían ocupado los espacios técnicos, políticos y administrativos de la burocracia, sin embargo, las nuevas necesidades influyeron en que gradualmente se establecieran profesiones con un sentido más especializado hacia la cuestión económica. Fue el caso de la licenciatura en Economía, creada precisamente en 1929 en principio, como una sección de la Escuela Nacional de Jurisprudencia de la Universidad Nacional, pero posteriormente, en 1935, se logró establecer la Escuela Nacional de Economía. ${ }^{3}$ La creación del Instituto Politécnico Nacional al año siguiente abonó a la lógica de creación de espacios generadores de técnicos, profesionistas e investigadores que contribuyeran a los procesos productivos industriales.

Para la década de los cuarenta, la necesidad de dicha mano de obra especializada, útil en la expansión de los sectores secundario y terciario de la economía, tanto para el sector público como el privado, implicó un significativo giro en las relaciones entre el Estado y la Universidad Nacional que devino en una nueva Ley Orgánica en 1945, en la que se consignaba el carácter de la casa de estudios como organismo descentralizado del Estado, adquiriendo así, un papel estratégico dentro del modelo de desarrollo implementado en esos años, cuyo eje fue precisamente la industrialización. De igual forma se crearon instituciones de carácter privado como el Instituto Tecnológico de Estudios Superiores de Monterrey, destinado a atender las demandas de mano de obra capacitada de los industriales de esa ciudad, y el Centro Cultural Universitario, que posteriormente se convertiría en la Universidad Iberoamericana, ambas instituciones vieron la luz en 1943.

En materia de investigación, en 1940 se creó a instancias de Jesús Silva Herzog, entonces director de la Escuela Nacional de Economía, el Instituto de

\footnotetext{
${ }^{3}$ Aunque al año siguiente se propuso su eliminación en sesión del Consejo Universitario, "Parece que la iniciativa partió de un grupo de contadores, celosos de los futuros economistas, que según creían, equivocadamente, podrían hacerles una indeseable y peligrosa competencia profesional". Finalmente, gracias a la intervención de Miguel Palacios Macedo y de Jesús Silva Herzog, se votó a favor de mantener la nueva licenciatura. (Silva, 1979, 59).
}

La Revista Estudios es editada por la Universidad de Costa Rica y se distribuye bajo una Licencia Creative Commons Atribución-NoComercial-Compartirlgual 3.0 Costa Rica. Para más información envíe un mensaje a revistaestudios.eeg@ucr.ac.cr. 
ISSN 1659-3316

Junio 2019-Noviembre 2019

Lozano Trejo Joaquín

Investigaciones Económicas de la Universidad Nacional, que en sus orígenes "atendió temas de organización e investigación industrial, siendo parte constitutiva de la propia Escuela." (Domínguez, 2007, 41)

Bajo esa lógica, ingenieros, economistas, abogados, contadores, entre otros profesionales, fueron incorporándose a los aparatos burocráticos dentro de los departamentos técnicos que fueron creados para sustentar las decisiones de carácter político. La tradicional hegemonía que habían tenido los abogados en la ocupación de cargos públicos, así como en el desempeño intelectual de las diversas ramas de conocimiento, se fue perdiendo con las nuevas necesidades en favor de los ingenieros y economistas. En relación con los ingenieros, refiriendo particularmente a la rama civil, se afirma que:

[...] de la dinámica revolucionaria emergieron condiciones que exigieron una promoción cuantitativa y cualitativa de la infraestructura, efecto de un nuevo pacto político y de la búsqueda de alternativas al proceso de acumulación vigente durante la dictadura. Ambos elementos se fueron configurando a raíz de la desintegración de la gran propiedad porfiriana y de la puesta en marcha de una reforma agraria que solicitaba optimar la producción y activar y diversificar la actividad comercial con base en la apertura de nuevas vías de comunicación. (Domínguez, 2013, 91)

Evidentemente, esta circunstancia también opera en términos explicativos en la comprensión de la relevancia que al respecto también tuvieron los ingenieros de la Escuela Nacional de Agricultura a partir del periodo posrevolucionario. Por su parte, los economistas respondieron a las necesidades de mejoramiento de la administración, tanto pública como de las empresas privadas:

\section{(c) (i) (-)}

La Revista Estudios es editada por la Universidad de Costa Rica y se distribuye bajo una Licencia Creative Commons Atribución-NoComercial-CompartirIgual 3.0 Costa Rica. Para más información envíe un mensaje a 
Los Profesionales en economía vendrán a llenar una necesidad que la vida impone y exige imperativamente [...] en un país como el nuestro, que ha realizado en los últimos años reformas políticas y sociales de importancia, la Universidad Nacional no preparaba técnicos capaces de cooperar en la organización definitiva de estas reformas, pero ahora la Universidad, no sólo con el propósito de suministrar a la Administración Pública de un técnico mejor preparado que el Abogado para el estudio de las cuestiones sociales y económicas, sino principalmente con el deseo de formar un profesional útil en el mejoramiento y organización de las industrias y empresas privadas, ha creado la carrera de Licenciado en economía. ${ }^{4}$ (Mariño, 2002, 24)

Más allá de las especificidades profesionales y epistémicas, lo cierto es que las dependencias gubernamentales empezaron a contar con una diversidad de elementos técnicos cada vez más especializados en determinadas tareas, principalmente las asociadas a la generación de infraestructura y de indicadores útiles para la administración. Es importante señalar que las acciones emprendidas o impulsadas desde la esfera gubernamental, no implicaron, como lo afirma Domínguez en el caso de la ingeniería civil, "la promoción de la ciencia y tecnología en general, sino el aprovechamiento de una práctica específica", (Domínguez, 2013, 91) lo que aplica perfectamente para el resto de las áreas del conocimiento que se desarrollaron con el fin de generar profesionistas útiles a los objetivos del modelo de acumulación mexicano.

Por lo tanto, las ideas generadas a la luz del análisis técnico no siempre fueron compatibles con las tomadas al calor de las inercias políticas de quienes se encontraban en los puestos últimos de decisión. En el caso específico de México, Vernon afirma que para esos años aún existía una diferencia hasta cierto punto notable entre técnicos y políticos. Con respecto a los primeros señala que, a pesar de sus diferencias ideológicas, tuvieron "una ideología en común que, inyectada en el aparato del gobierno, constituye una fuerza poderosa en la conformación del comportamiento del sector público." (Vernon, 1966, 154) Y concluye que más que

\footnotetext{
${ }^{4}$ Declaraciones del rector Antonio Castro Leal a la prensa en El Economista, 18 de febrero de $1929 .$.

La Revista Estudios es editada por la Universidad de Costa Rica y se distribuye bajo una Licencia Creative Commons Atribución-NoComercial-Compartirlgual 3.0 Costa Rica. Para más información envíe un mensaje a revistaestudios.eeg@ucr.ac.cr.
} 
ISSN 1659-3316

Lozano Trejo Joaquín

influir directamente en la política, su fuerza radicó en su capacidad "para elegir alternativas técnicas que son presentadas a sus amos políticos" (Vernon, 1966, 155).

Para este autor, es claro que las concepciones sobre el desarrollo de los técnicos mexicanos, al igual que el de muchos latinoamericanos, coincidieron y en muchos sentidos estuvieron asociadas a los planteamientos de Raúl Prebisch, ${ }^{5}$ secretario ejecutivo de la Comisión Económica para América Latina. Desde estas perspectivas, los técnicos mexicanos plantearon la necesidad de dejar la dependencia de las exportaciones de materias primas y las importaciones de bienes manufacturados; por lo que era necesario aumentar la producción del sector industrial, preferentemente con capital nacional.

Las propuestas de los técnicos también giraron, de acuerdo con este autor, en torno a una mayor racionalización y planificación de la intervención del Estado en la economía, las que por lo general no coincidían con las acciones de los políticos. Y precisamente, la creación de la Oficina de Investigaciones Industriales (OII) del Banco de México se enmarca en este proceso de profesionalización de la burocracia gubernamental, pero dentro de las especificidades que institucionalmente tenía el Banco de México en los años en que la industrialización fue el eje de la economía nacional. En este sentido, las tareas desempeñadas por la Oll, más que contribuir a la proyección planificada de la industrialización nacional, respondieron al pragmatismo de las decisiones políticas en el marco de colaboración del Banco de México con las acciones de carácter gubernamental.

Para entonces, esta institución contaba con su propio Departamento de Investigaciones Económicas, ${ }^{6}$ (Anaya, 2011, 52) el cual proporcionaba informes regulares sobre indicadores monetarios y financieros útiles para la valoración del

\footnotetext{
5 Incluso se le invitó a dar una serie de conferencias en 1944 y posteriormente se le hizo la invitación para que trabajara de manera permanente en el Banco de México la cual fue declinada. "Acta 1131", Libro de Actas del Consejo de Administración del Banco de México no. 17, 22 de mayo de 1946, AHBM, fs. 66.

${ }^{6}$ Este departamento surgió durante la gestión en el Banco de México de Luis Montes de Oca, precisamente ante la falta de estadísticas confiables. Para su instalación se apoyó de expertos del Banco de la Reserva Federal.
}

La Revista Estudios es editada por la Universidad de Costa Rica y se distribuye bajo una Licencia Creative Commons Atribución-NoComercial-Compartirlgual 3.0 Costa Rica. Para más información envíe un mensaje a revistaestudios.eeg@ucr.ac.cr. 
ISSN 1659-3316

Junio 2019-Noviembre 2019

Lozano Trejo Joaquín

funcionamiento del Banco, así como del marco económico nacional. Incluso en algunos casos los estudios realizados por este departamento se referían a aspectos productivos ante los que el Banco de México sentía obligación de intervenir por medio de la realización de gestiones con otras dependencias gubernamentales para su atención, por ejemplo, en relación con un informe presentado por Investigaciones Económicas acerca del posible aprovechamiento de diversos productos:

...el señor Director propuso y el Consejo aprobó, que el Banco gestione ante la Secretaría de Hacienda el aprovechamiento de muchos productos que se tiran, como la melaza que pudiera transformarse en alcohol para exportación, debidamente controlado para evitar que vaya al consumo nacional, ya que la exportación misma de las mieles tropieza con varias dificultades, entre otras la falta de envases; melaza que actualmente se pierde y cuya transformación en alcohol no requiere de nuevos equipos ni constituye una industria nueva y en cambio beneficiaría la economía nacional buscándole nuevo mercado, etc. etc. ${ }^{7}$

\section{Gonzalo Robles y la Oficina de Investigaciones Industriales}

Inicialmente, la creación de la Oficina de Investigaciones Industriales en 1941 fue el resultado del empeño de un conjunto de hombres que desde la década de los veinte había formado parte de la reconstrucción que emprendieron los gobiernos de Álvaro Obregón y Plutarco Elías Calles, aportando la visión técnica para establecer políticas económicas y sociales que le dieran viabilidad al Estado surgido de la revolución. Así, intereses académicos y aspiraciones de inserción en la burocracia de grupo, encontraron cabida dentro de las necesidades que las dependencias gubernamentales tuvieron para reordenar la economía del país e impulsar proyectos de desarrollo nacional, en este caso, la intención de Banco de México de contribuir a los procesos de industrialización nacional.

\footnotetext{
7 “Acta 902”, Libro de Actas del Consejo de Administración del Banco de México no. 14, 17 de diciembre de 1941, AHBM, fs. 186-187.

La Revista Estudios es editada por la Universidad de Costa Rica y se distribuye bajo una Licencia Creative Commons Atribución-NoComercial-Compartirlgual 3.0 Costa Rica. Para más información envíe un mensaje a revistaestudios.eeg@ucr.ac.cr.
} 
ISSN 1659-3316

Lozano Trejo Joaquín

La experiencia y conocimiento de Robles fueron valorados entonces para formar parte como consultor del Banco de México, institución a la que estuvo ligado desde entonces y hasta su muerte en 1980. Como ya apuntamos, esa tarea implicó el establecimiento de la Oficina de Investigaciones Industriales. Se podría decir que la propia Oficina, entendida como un proyecto independiente que buscaba aportar elementos para resolver la situación de la producción nacional, principalmente de la rama industrial, tuvo su propia historia desde que Gonzalo Robles dirigió el Banco Nacional Hipotecario Urbano y de Obras Públicas.

Sin que tengamos elementos para delinear de manera más amplia su trayectoria, si podemos deducir la afirmación anterior de una referencia que hizo el mismo Robles en un documento leído como anexo a un trabajo titulado "Los pueblos atrasados, sus problemas y su planeación económica", presentado para la "Memoria de la Reunión de Expertos sobre Problemas de Planeación Económica y Ejecución de Programas de Fomento en países poco desarrollados", a fines de mayo de 1950 en la ciudad de San Juan, de Puerto Rico.

En el anexo presentado con el título de "Ideas para la realización de investigaciones económico-industriales con fines de planeación", el autor inició con una referencia que nos habla sobre la primera Oficina de Investigaciones Industriales:

Las ideas generales contenidas en este pequeño ensayo quedaron establecidas hace bastantes años en conexión con las actividades de una efímera Oficina de Investigaciones Industriales que el autor creó siendo director del Banco Nacional Hipotecario, al que correspondía el fomento industrial del país, entonces muy incipiente. Posteriormente se revisaron, con motivo de un intento de creación de un Instituto de Investigaciones Económicas por el Banco de México, la Nacional Financiera y el Banco de Comercio Exterior, que tenía interés especial en realizar estudios concretos sobre producción o cultivo y comercio de aquellos artículos que de preferencia entran en nuestro comercio internacional, todo dentro del cuadro de conjunto de la economía del país. El plan no fue aceptado. En aquella época el ensayo tomó casi la forma actual. (Robles, 1982, 155)

\section{(C) $(00$}

La Revista Estudios es editada por la Universidad de Costa Rica y se distribuye bajo una Licencia Creative Commons Atribución-NoComercial-CompartirIgual 3.0 Costa Rica. Para más información envíe un mensaje a 
ISSN 1659-3316

Lozano Trejo Joaquín

Otros documentos también nos refieren sobre este antecedente relacionado con el

Banco Nacional Hipotecario. Uno de ellos hace mención a una Comisión de Investigaciones Industriales que presentaba un proyecto de trabajo en el que se consideraba un amplio análisis de la situación de la industria en el país que, por cierto, ya se había iniciado con una serie de visitas sistemáticas a industrias de la capital y de algunos estados de la República. ${ }^{8}$ Lamentablemente los documentos mencionados no tienen una fecha que nos permita situarlos de manera precisa, pero hacen referencia a su existencia como parte del mencionado Banco Nacional Hipotecario y al hacer referencia de la existencia de la Nacional Financiera, podríamos ubicarlo posterior a 1934, es decir, durante el periodo cardenista.

Sin embargo, es importante resaltar que además de que una de las versiones del documento -encontramos dos de ellas- parece estar firmada por Robles, las líneas de trabajo que plantea son muy semejantes a las que luego estableció la Oficina de Investigaciones Industriales del Banco de México. Por otro lado, varios de los nombres que aparecen en el listado del personal que integró o integraría la Comisión de Investigaciones Industriales, como los de Emilio Alanís Patiño, ${ }^{9}$ Alfonso González Gallardo, Eduardo Villaseñor y el propio Gonzalo Robles, aparecerán posteriormente en la dependencia motivo de nuestro estudio. ${ }^{10}$ Durante la existencia de esta Comisión se logró la realización de

\footnotetext{
8 "Proyecto de trabajo de la Comisión de Investigaciones Industriales", s/f, Archivo General de la Nación [en adelante AGN], Fondo Gonzalo Robles, caja 22, exp. 4.

${ }^{9}$ Ingresó a la Escuela Nacional de Agricultura (San Jacinto, D.F) en 1922 y terminó sus estudios de Ingeniero Agrónomo con especialidad en Industrias Agrícolas en 1928 (Chapingo). Realizó estudios de posgrado en la Facultad de Ciencias Matemáticas, estadísticas y Actuariales de la Real Universidad de Roma. Fue Técnico del Departamento de Estadística Nacional (1929-1930), Jefe de la Oficina Central de los Censos (1933-1937), Director General de Estadística (1938-1941), Jefe del Departamento de Estadística de la Comisión Nacional de Irrigación (1942-1943), Gerente de la Constructora El Roble (1943-1948), Funcionario de la Comisión Económica para América Latina, Naciones Unidas (1949-1951), Jefe de Planeación Industrial, Departamento de Investigaciones Industriales del Banco de México, (1951-1954), Subjefe y Jefe del Departamento de Investigaciones Industriales del Banco de México (1954-1965), Subdirector General del Banco Nacional Agropecuario (1965-1975), Asesor del Secretario de Agricultura y Recursos Hidráulicos (1983-1988).

${ }^{10}$ La lista completa es la siguiente: Emilio Alanís Patiño, Carlos Arroyo, Pablo Azcué Mancera, René Becerra, Ing. Bernard, George D. Camp, Félix Chaires, Daniel Cosío Villegas, Jorge Cuesta, Dante Cusi, Moisés de la Peña, Luis Enrique Erro, Antonio Espinosa de los Montero, Ramón Fernández y Fernández, José Gama, Valentín Gama, Gonzalo González, Alfonso González Gallardo, Herminio Govea, Lic. Ponciano Guerrero, Salvador Guerrero, Pascual Gutiérrez Roldan, Mario Javier Hoyo, Heuer, Roberto López, Héctor
}

\section{(c) (i) (2)}

La Revista Estudios es editada por la Universidad de Costa Rica y se distribuye bajo una Licencia Creative Commons Atribución-NoComercial-CompartirIgual 3.0 Costa Rica. Para más información envíe un mensaje a revistaestudios.eeg@ucr.ac.cr. 
algunos estudios que después pasarían a formar parte del Banco Nacional Obrero de Fomento Industrial. ${ }^{11}$

Un antecedente más, que habla de la interacción de estos profesionistas en relación con los estudios económicos, es el que menciona Manuel Bravo respecto a la creación, junto con Robles, de un Laboratorio de Organización e Investigación Industrial en la Escuela de Economía de la Universidad Nacional:

Visita con Gleason Álvarez a la casa de Robles: primera manifestación de la cariñosa hospitalidad de Melita, para conversar sobre la organización del Laboratorio de Organización e Investigación Industrial en la escuela de Economía. Lo creamos en 1938. Mi primer grupo de asesores: González Aparicio, Mario Souza, Gleason Álvarez, Alfonso Goldschmidt, con un solo funcionario como director, secretario, impresor y mensajero. Silva Herzog le dio vida institucional y en este primer año inusitado experimento pedagógico- los Laboratorios de la Escuela de Economía acogieron a jóvenes estudiantes, entonces promesa y hoy realidad, entre ellos nuestro querido amigo el Lic. Ernesto Fernández Hurtado. $^{12}$

En efecto, de estas reuniones complementadas con el apoyo institucional de la dirección de la Escuela Nacional de Economía, surgió el Laboratorio de Organización e Investigación Industrial, fundado el 7 de septiembre de 1939, el cual sería más bien un antecedente directo del Instituto de Investigaciones Económicas. (Mariño, 2002, 29)

De tal forma que dentro del ambiente gubernamental se formaba una cohorte de hombres que, surgidos de las instituciones de educación superior nacionales, se incorporaron al servicio público tratando de contribuir a la solución,

\footnotetext{
Lazos, A. Luna Olmedo, Ernesto Martínez de Alva, Emigdio Martínez Adame, Roberto Meneses, Ing. Orozco, Ocádiz, Enrique Ortiz, Luis Pagés, Constantino Pérez Duarte, José Antonio Rivera, Rafael Sánchez de Tagle, Javier Sánchez Mejorada, Miguel Santa María, Enrique Sarro, Jesús Silva Herzog, Mario Sousa, Eduardo Villaseñor, Fulvio Zama, Francisco Zamora, Manuel Zebada. "Personal”, AGN, Fondo Gonzalo Robles, caja 22, exp. 4.

11 "Relación de los estudios realizados por la Comisión de Investigaciones industriales durante el tiempo en que dependió de esta institución y que fueron traspasados al Banco Nacional Obrero de Fomento Industrial”, s/f, AGN, Fondo Gonzalo Robles, caja 22, exp. 4.

12 Manuel Bravo, "Participación del Departamento en el desarrollo económico e industrial del país", en Celebración del XXV aniversario del departamento de Investigaciones Industriales, 27 de octubre de 1966, Banco de México, Archivo Histórico del Banco de México en adelante AHBM, caja 18, exp. 5, fs. 17
}

\section{(a) $\mathbb{Q} \otimes(0)$}

La Revista Estudios es editada por la Universidad de Costa Rica y se distribuye bajo una Licencia Creative Commons Atribución-NoComercial-CompartirIgual 3.0 Costa Rica. Para más información envíe un mensaje a revistaestudios.eeg@ucr.ac.cr. 
ISSN 1659-3316

Lozano Trejo Joaquín

desde su visión y desde distintas trincheras, de los problemas que se presentaban a la posibilidad de un desarrollo económico nacional. ${ }^{13}$ En el caso del grupo al que nos referimos, liderado en gran parte por el ingeniero Robles, tenía una preocupación particular por el fomento industrial y la necesidad de establecer esquemas de planeación que redundaran en un crecimiento sostenido de la economía. Las coordenadas institucionales en que se forjó y desenvolvió este grupo, se encuentran en la Escuela Nacional de Agricultura, la Escuela Nacional de Economía de la Universidad Nacional, así como en las instituciones crediticias del sector público.

Los destinos de estos esfuerzos en materia de análisis de la industria se vieron limitados por el propio carácter secundario que tuvo la industria en los primeros gobiernos posrevolucionarios. Pero el sustancial crecimiento que empezó a tener la industria nacional a principios de la década de los cuarenta planteó la posibilidad de que esta actividad fuera el eje alrededor del cual se proyectara el desarrollo económico nacional. En este contexto, la existencia de una entidad dedicada a investigar sus condiciones y circunstancias, con el fin de integrarla a un esquema de planificación más amplio, cobró mayor sentido en ese momento.

Diversas dependencias públicas buscaron implementar políticas y estrategias mediante las que se pudieran contribuir, desde sus funciones específicas, a las nuevas proyecciones gubernamentales. A nivel federal, la actividad de la investigación científica orientada a la resolución de los problemas económicos nacionales se concentró en organismos que buscaron coordinar los diversos esfuerzos en la materia, intentando darles una determinada orientación. Ya en el sexenio cardenista se había establecido el Consejo Nacional de la

\footnotetext{
${ }^{13}$ A partir de la formación de economistas, surgieron departamentos especializados en diversas secretarías de estado y organismos financieros públicos. Ferrocarriles Nacionales de México organizó su Oficina de Estudios Económicos (1930), la Secretaría de Economía Nacional, su Departamento de Estudios Económicos (1933), la Secretaría de Hacienda y Crédito Público, su Oficina de Investigaciones Económicas (1934). Además del Banco de México, el Banco Nacional de Comercio Exterior y la Nacional Financiera, establecieron sus departamentos destinados a la investigación económica.
}

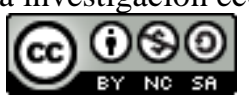

La Revista Estudios es editada por la Universidad de Costa Rica y se distribuye bajo una Licencia Creative Commons Atribución-NoComercial-CompartirIgual 3.0 Costa Rica. Para más información envíe un mensaje a revistaestudios.eeg@ucr.ac.cr. 
ISSN 1659-3316

Junio 2019-Noviembre 2019

Lozano Trejo Joaquín

Educación Superior y la Investigación Científica, ${ }^{14}$ con el que se pretendió organizar un sistema de educación superior que, entre otros aspectos, orientará los objetivos de la investigación científica que se desarrollará en ese tipo de instituciones. Su carácter de órgano consultor y, por lo tanto, con limitada capacidad ejecutiva; en conjunción con la oposición que tuvo de la Universidad Nacional, derivó en una muy escasa influencia y concreción de proyectos al respecto.

Para el periodo de Manuel Ávila Camacho, se transformó en la Comisión Impulsora y Coordinadora de la Investigación Científica, con la finalidad de "fomentar y coordinar todas las investigaciones técnicas y científicas que se llevan a cabo en el país, con objeto de cooperar al mejoramiento de la agricultura y de la industria...", ${ }^{15}$ y en 1950 fue sustituida por el Instituto Nacional de Investigación Científica, creada por decreto presidencial, con el objeto del "fomento, desarrollo y la coordinación de las investigaciones que se realicen en la República Mexicana relacionadas con las ciencias matemáticas, físicas, químicas, biológicas y geológicas, así como con las ciencias aplicadas derivadas de ellas;..." ${ }^{16}$ Las diferencias, entre la nueva institución y sus antecesoras, radicaba más en cuestiones de forma que de fondo, al final, la pretendida coordinación de los esfuerzos en la materia se limitó al financiamiento de diversas investigaciones, el otorgamiento de becas y el apoyo para publicaciones científicas.

En el caso del Banco de México, durante el sexenio avilacamachista fue designado como su director general Eduardo Villaseñor, quien invitó al ingeniero Gonzalo Robles a participar como consultor de la dirección. Como parte de esta tarea de consultoría, se creó la Oficina de Investigaciones Industriales que, en la estructura del Banco de México, complementaría los trabajos del departamento de

\footnotetext{
14 "Decreto que crea el Consejo Nacional de la Educación Superior y la Investigación Científica", Diario Oficial de la Federación, 30 de octubre de 1935, p. 1078.

15 "Ley de la Comisión Impulsora y Coordinadora de la Investigación Científica", Diario Oficial, 31 de diciembre de 1942, p. 13.

16 "Decreto que crea el Instituto Nacional de la Investigación Científica", Diario Oficial, 28 de diciembre de 1950, p. 6-9.
}

La Revista Estudios es editada por la Universidad de Costa Rica y se distribuye bajo una Licencia Creative Commons Atribución-NoComercial-CompartirIgual 3.0 Costa Rica. Para más información envíe un mensaje a revistaestudios.eeg@ucr.ac.cr. 
Revista Estudios, (38), 2019.

Junio 2019-Noviembre 2019

ISSN 1659-3316

Lozano Trejo Joaquín

investigaciones económicas ya existente en ese momento. El mismo Robles justificaba la creación de esta Oficina afirmando que, un banco central, sin dejar de lado sus actividades principales, debería de ser "el motor primario de la economía", por lo que dentro de los departamentos que debían integrar esta institución, no podría faltar uno encargado de investigaciones referentes a la industria. $^{17}$

En efecto, para el Banco de México significaba tener una participación más activa en el fomento a la actividad industrial tanto como resultado de su integración en el marco institucional mexicano, como en respuesta a compromisos o iniciativas de carácter internacional, principalmente con dependencias norteamericanas. En este sentido, el Banco participó en la creación de diversas instancias que contribuyeran desde distintas perspectivas al desarrollo de la industrialización. Por ejemplo, propuso la creación del Instituto Mexicano de Investigaciones Económicas, ${ }^{18}$ el cual, debido al ambicioso plan de trabajo proyectado, se decidió inicialmente dejarlo en manos de El Colegio de México y teniendo por objeto principal, "realizar investigaciones y estudios con el propósito de alcanzar conclusiones de carácter general respecto a la más conveniente política económica para México en los aspectos fundamentales de esta", ${ }^{19}$ el financiamiento inicial correría a cargo del Banco de México, de Nacional Financiera y del Banco Nacional de Comercio Exterior. ${ }^{20}$

Así, aprovechando la experiencia e intereses del grupo de ingenieros y economistas encabezados por Gonzalo Robles, el Banco de México contó con un órgano técnico a partir del cual pudo extender sus funciones en el marco del proyecto económico de esos años, emitiendo opiniones técnicas, colaborando

\footnotetext{
${ }^{17}$ Gonzalo Robles, "El Banco de México”, AGN, Fondo Gonzalo Robles, caja 20, exp. 4, fs. 2

18 “Acta 988", Libro de Actas del Consejo de Administración del Banco de México no. 15, 25 de agosto de 1943, AHBM, fs. 167-168.

${ }^{19}$ Acta 990", Libro de Actas del Consejo de Administración del Banco de México no. 15, 8 de septiembre de 1943, AHBM, fs. 171-173.

${ }^{20}$ Sin embargo, en una sesión posterior se decidió finalmente que se convirtiera en una entidad autónoma sostenida financieramente por medio de un fideicomiso que al terminar transfiriera sus bienes a la Universidad Nacional. "Acta 1030”, Libro de Actas del Consejo de Administración del Banco de México no. 16, 14 de junio de 1944, AHBM, fs. 48-49.
}

\section{(a) $(\Theta \odot$}

La Revista Estudios es editada por la Universidad de Costa Rica y se distribuye bajo una Licencia Creative Commons Atribución-NoComercial-CompartirIgual 3.0 Costa Rica. Para más información envíe un mensaje a revistaestudios.eeg@ucr.ac.cr. 
Revista Estudios, (38), 2019.

Junio 2019-Noviembre 2019

ISSN 1659-3316

Lozano Trejo Joaquín

desde esta perspectiva con otras dependencias gubernamentales, financiando investigaciones públicas y particulares, formando recursos humanos especializados, promoviendo la creación de instituciones orientadas a la investigación y producción de tecnología, y sirviendo de enlace con organismos de carácter internacional.

\section{La orientación de la OlI}

Evidentemente, la responsabilidad de la Oficina recayó en el ingeniero Robles, quien llevó como subjefe a Manuel Bravo. Para encabezar los estudios proyectados el equipo se integró con personas con las que habían venido trabajando en otros proyectos afines como Manuel Gleason y Alfonso González Gallardo; para los trabajos específicos sobre la exploración de los recursos minerales del país se contrató a dos expertos españoles: Luis Torón y Adrián Esteva $^{21}$ a los que se les unió después Salvador Cortés Obregón. La labor de investigación sería complementada con pasantes de la carrera de economía, principalmente, o de alguna ingeniería.

Se concretó así un equipo conformado por ingenieros y economistas que gradualmente se enriquecería con la preparación de especialistas formados en el extranjero en áreas específicas de la industria y la economía gracias al Programa de Becas que en 1944 empezó a llevar a cabo el Banco de México a través de esa misma Oficina.

Así, inició sus labores esta dependencia que tenía como uno de sus objetivos principales efectuar los estudios necesarios acerca de las posibilidades industriales del país, a través de la obtención de información sobre los recursos de este. Sus principales metas se resumían en:

\footnotetext{
${ }^{21}$ Asilado español que logró su Carta de naturalización como mexicano en 1943. Acervo Histórico Genaro Estrada. Secretaria de Relaciones Exteriores, "Carta de naturalización 365/43. Adrián Esteve Torres". Exp. VIII/521.2(46)/8050.
}

\section{(c) (1) (2)}

La Revista Estudios es editada por la Universidad de Costa Rica y se distribuye bajo una Licencia Creative Commons Atribución-NoComercial-CompartirIgual 3.0 Costa Rica. Para más información envíe un mensaje a revistaestudios.eeg@ucr.ac.cr. 
ISSN 1659-3316

Lozano Trejo Joaquín

1. Estudiar las bases de la política primordial para la industrialización, como parte de la política que rige el desarrollo económico y social del país.

2. Determinar las políticas secundarias del desarrollo industrial relacionadas con los siguientes aspectos: a) Factores limitantes, que pueden ser económicos, técnicos, de dirección y administración; c) Regiones o entidades federativas y centros industriales.

3. Mantener al corriente el conocimiento objetivo del desarrollo industrial mexicano." (Banco de México, 1963, p. 6-7)

En la proyección de las investigaciones a desarrollar por este equipo de trabajo, jugó un papel importante las concepciones ideológicas que al respecto sostenía el propio Robles, según las cuales, en gran medida respondían a las circunstancias de un país que históricamente había fundado su actividad económica en la producción de materias primas, bienes alimenticios y extracción de recursos naturales, útiles a la industria de otras naciones. Circunstancia compartida con el resto de los países de América Latina, Robles las resumía al abordar las dificultades para que la región emprendiera la industrialización en la coyuntura de esos años:

Con ese nombre conocemos a un grupo numeroso, pero desarticulado de naciones, las nuestras, que son políticamente independientes, pero económicamente subordinadas a los grandes países capitalistas, es decir, los industriales. Ha sido pastora, agricultora y minera y ha vivido principalmente de cambiar materias primas y sustancias alimenticias por los productos manufacturados de aquéllas. Es de tradición ibérica, no industrial...

Cree llegado su momento para la gran industrialización... ¿La guerra le brinda oportunidad única? ¿La obliga a intentarlo? Muchos lo creyeron así, algunos todavía no lo creen, pero otros temen que haya tocado demasiado tarde a la puerta, o demasiado temprano; cuando menos, en momento poco oportuno. ${ }^{22}$ (Robles, 1982, p. 31)

Más allá de la oportunidad del momento en que algunos países de América Latina, entre ellos México, aspiraban a industrializar su actividad económica, señalaba los

\footnotetext{
22 Gonzalo Robles, "Obstáculos a la industrialización de los países latinoamericanos". Este texto fue
} presentado y discutido en el seminario sobre la guerra celebrado en diciembre de 1943.

\section{(c) (1) 8 (9)}

La Revista Estudios es editada por la Universidad de Costa Rica y se distribuye bajo una Licencia Creative Commons Atribución-NoComercial-CompartirIgual 3.0 Costa Rica. Para más información envíe un mensaje a 
Revista Estudios, (38), 2019.

Junio 2019-Noviembre 2019

ISSN 1659-3316

Lozano Trejo Joaquín

factores que habría que poner en juego para lograrlo. En principio hacía hincapié en la necesidad de realizar un inventario de los recursos naturales con que contaban dichos países, con el fin de contar con los mejores materiales aplicables a la industria. Su papel como combustibles, particularmente del petróleo, la electricidad y el carbón, resultaba de tal importancia, que demandaba de la intervención estatal, particularmente en el tratamiento técnico de este aspecto:

La riqueza en recursos es una función de la técnica, tanto por lo que hace a los métodos de explotación como a los de utilización (o no utilización); a la vez que es una función de la economía, ya que la cantidad de recursos que se puede extraer (siempre que los haya) depende del precio. (Robles, 1982, p. 31)

La cuestión del conocimiento real de los recursos naturales por medio de una instancia técnica no era nueva en el caso de nuestro país. Ya Salvador Alvarado, general revolucionario de la facción sonorense, en 1919 había manifestado la necesidad de crear una Oficina de Recursos Naturales, cuya tarea primera tendría que ser el levantamiento de un Inventario General de Recursos Naturales con el objetivo de estudiar las posibilidades para su mejor aprovechamiento y desarrollo. Para ello, resultaba necesario:

Iniciar por medio de los personales técnicos de los departamentos correspondientes, 0 por comisiones especiales, estudios e investigaciones relativos a la aplicación de los métodos más científicos y prácticos para la explotación de las riquezas naturales, dando toda clase de facilidades a los interesados -particulares o compañías- para que obtengan las enseñanzas e informaciones que soliciten, relacionadas con el conocimiento de nuestros recursos naturales y de los métodos que deban seguirse para su explotación y aprovechamiento. (Alvarado, 1919, p. 48).

Por lo tanto, la propuesta de Robles nos habla no sólo de la influencia que tenía como producto de su participación en los primeros gobiernos posrevolucionarios que se plantearon la reconstrucción del país, sino también de que el conocimiento

\section{(c) (i) (2)}

La Revista Estudios es editada por la Universidad de Costa Rica y se distribuye bajo una Licencia Creative Commons Atribución-NoComercial-CompartirIgual 3.0 Costa Rica. Para más información envíe un mensaje a 
ISSN 1659-3316

Junio 2019-Noviembre 2019

Lozano Trejo Joaquín

cabal de los recursos naturales de la nación seguía siendo una tarea pendiente, ahora necesaria en el marco de su aplicación a la empresa industrial.

El desarrollo de la técnica aplicada al estudio de los recursos naturales y al manejo de la industria, tenía que ver según Robles: “...con el genio, pero debe mucho al método, y recibe su estímulo vital de la necesidad", (Robles, 1982, p.47) por lo que emprender un proyecto de carácter industrial, demandaba de forma imprescindible de la formación de cuadros técnicos: "de acuerdo con un plan de conjunto, pero para fines específicos. Esta tarea es principalmente, y sobre todo para empezar, obra de Estado." (Robles, 1982, p.49)

Por lo tanto, de acuerdo con Robles, la planificación de un proyecto de desarrollo industrial en un país como México, tendría que iniciar por un conocimiento amplio de los recursos minerales existentes. De tal forma que, durante esta etapa inicial de la OlI, los trabajos se concentraron, en la evaluación de los recursos naturales con que contaba la nación, con el fin de tener un panorama de las posibilidades de su aplicación en el desarrollo industrial.

\section{Conclusiones}

Al presentar la trayectoria profesional de Gonzalo Robles, realizamos un recorrido a grandes trazos por la construcción institucional del Estado que surgió de la Revolución mexicana y, por ende, de las grandes problemáticas que tuvo que enfrentar para conferirle fisonomía al México del siglo XX.

En este sentido, se puede valorar la trascendencia que tuvo la intensa labor de un costarricense que, desde su condición latinoamericana, aportó su talento y energías a las circunstancias que se le presentaron en su nueva patria mexicana, al igual que otros latinoamericanos que llegaron a México en las primeras décadas del siglo y se insertaron en los ámbitos académicos, culturales e intelectuales.

Al adoptar en su desempeño como funcionario una posición nacionalista, en realidad adoptaba la postura común a América Latina en su lucha por matizar la

\section{(c) (i) (2)}

La Revista Estudios es editada por la Universidad de Costa Rica y se distribuye bajo una Licencia Creative Commons Atribución-NoComercial-CompartirIgual 3.0 Costa Rica. Para más información envíe un mensaje a 
ISSN 1659-3316

Junio 2019-Noviembre 2019

Lozano Trejo Joaquín

dependencia política y principalmente económica con respecto a las potencias industrializadas. Su pensamiento con respecto a los procesos de industrialización que a mediados de siglo se impulsaban en México, pero también en otros países del subcontinente es muestra de ello.

Condicionada por los efectos de la Segunda Guerra Mundial, la industrialización latinoamericana operaba en función de los intereses de las potencias enfrentadas. Sin embargo, tratando de sacar provecho de las circunstancias, Robles compartía las posturas que promovían un desarrollo industrial con mayor margen de autonomía.

Sabedor de que el poder industrial de los europeos y Estados Unidos radicaba en gran parte en tener a su disposición las materias primas que por separado tenían los diversos países de América Latina, pugnaba por una integración de estas en beneficio de la región, al tiempo que se exploraba e inventariaban los recursos de las mismas para ampliar las posibilidades de su utilización en términos industriales sin depender del exterior. De igual forma promovió la planeación y mejoramiento de la productividad de la mano de obra por medio de becas que permitieran estudios en el extranjero.

En suma, un costarricense que, sin estar bajo los reflectores, contribuyó de manera significativa a la nación mexicana y de paso, dejo su pensamiento al servicio de América Latina.

\section{Fuentes}

\section{Archivos}

Archivo General de la Nación, Fondo Gonzalo Robles, CDMX

Archivo del Banco de México, Actas del Consejo de Administración del Banco de México, CDMX

Archivo Histórico Genaro Estrada. Secretaría de Relaciones Exteriores. CDMX

La Revista Estudios es editada por la Universidad de Costa Rica y se distribuye bajo una Licencia Creative Commons Atribución-NoComercial-CompartirIgual 3.0 Costa Rica. Para más información envíe un mensaje a revistaestudios.eeg@ucr.ac.cr. 


\section{Bibliografía}

Alvarado, S. (1919) La reconstrucción de México, Tomo I, México, J. Ballesca y Cía.

Anaya, L. (2011). El Banco de México y la economía cardenista. Economía, cambio institucional y reglas monetarias, México, Universidad Autónoma del Estado de Morelos-Miguel Ángel Porrúa.

Banco de México. (1963). Índice de monografías e informes técnicos del Departamento de Investigaciones Industriales, 1943-1962, México, Morales Hnos.

Dávalos, M. (2014). Gonzalo Robles: Una utopía sepultada, México, Instituto Nacional de Antropología e Historia-Ediciones el Tucán de Virginia.

Domínguez, R. (2013). La ingeniería civil en México, 1900-1940. Análisis histórico de los factores de su desarrollo, México, UNAM-IISUE.

Domínguez, R. (2007). Panorama general de la investigación en institutos y centros de humanidades de la Universidad Nacional durante el siglo XX, México, UNAM-Miguel Ángel Porrúa.

Gauss, S. (2010). Made in México. Regions, nation, and the state in the rise of Mexican industrialism, 1920s-1940s, USA, Pennsylvania State University Press, University Park.

Giles, Y. (1988) Gonzalo Robles y la industrialización de México. (Tesis de licenciatura). Facultad de Filosofía y Letras. México, D.F.

Mariño, A. (2002). Investigación en libertad. Historia del Instituto de Investigaciones Económicas, 1940-2000, México, UNAM-IIE.

Robles, G. (1982) Ensayos sobre el desarrollo de México, México, Fondo de Cultura Económica-Banco de México.

Silva, J. (1979). Una historia de la Universidad de México y sus problemas, México, Siglo XXI.

Vernon, R. (1966). El dilema del desarrollo económico de México, México, Diana.

Zebadúa, E. (1994). Banqueros y revolucionarios: la soberanía financiera de México, 1914-1929, México, FCE-COLMEX-FHA.

\section{(c) (i) (-)}

La Revista Estudios es editada por la Universidad de Costa Rica y se distribuye bajo una Licencia Creative Commons Atribución-NoComercial-CompartirIgual 3.0 Costa Rica. Para más información envíe un mensaje a 